\title{
Increased nitric oxide metabolites in exhaled breath condensate after exposure to tobacco smoke
}

\author{
B Balint, L E Donnelly, T Hanazawa, S A Kharitonov, P J Barnes
}

\begin{abstract}
Background-Cigarette smoking reduces the level of exhaled nitric oxide (NO) in healthy subjects, although the mechanism is unclear. NO is a highly reactive molecule which can be oxidised or complexed with other biomolecules, depending on the microenvironment. The stable oxidation end products of NO metabolism are nitrite and nitrate. This study investigated the effect of smoking on NO metabolites in exhaled breath condensate.

Methods-Fifteen healthy current smokers were recruited together with 14 healthy non-smokers. Measurement of exhaled NO, lung function, and collection of exhaled breath condensate were performed. Nitrite, nitrite + nitrate, S-nitrosothiols, and nitrotyrosine levels were measured. The effect of inhaling two cigarettes in smokers was also evaluated. The mean level of exhaled NO in smokers was significantly lower than in nonsmokers (4.3 (0.3) ppb $v 5.5(0.5) \mathrm{ppb}$, $\mathrm{p}<0.05$ ).
\end{abstract}

Results-There was no difference in the levels of nitrite, nitrite + nitrate, S-nitrosothiols, and nitrotyrosine in the exhaled breath condensate at the baseline visit between smokers and non-smokers. After smoking, nitrite + nitrate levels were significantly but transiently increased (from $20.2(2.8) \mu M$ to 29.8 (3.4) $\mu M$, $\mathbf{p}<0.05)$. There was no significant change in the levels of exhaled NO, nitrite, S-nitrosothiols, or nitrotyrosine 30 and 90 minutes after smoking.

Department of Thoracic Medicine, Imperial College School of Medicine at the National Heart and Lung Institute, Dovehouse Street, London SW3 6LY, UK B Balint

L E Donnelly

T Hanazawa

S A Kharitonov

P J Barnes

Correspondence to: Professor P J Barnes p.j.barnes@ic.ac.uk

Received 10 April 2000 Returned to authors 18 September 2000 Revised version received 17 November 2000 Accepted for publication 15 February 2001

Nitric oxide (NO) is a gaseous mediator which has an important role in several physiological processes in the respiratory tract including vascular regulation, neurotransmission, host defence, and cytotoxicity. ${ }^{12} \mathrm{NO}$ may be protective against oxidant induced cytotoxicity, but it may also contribute to respiratory tract injury via the interaction of $\mathrm{NO}$ with reactive oxygen species resulting in reactive nitrogen intermediates..$^{3-5}$ NO itself is a highly reactive molecule with a relatively short half life in vivo. ${ }^{5}{ }^{6}$ It can be oxidised or complexed with other biomolecules depending on the microenvironment. ${ }^{378} \mathrm{NO}$ can undergo a reaction with superoxide anions $\left(\mathrm{O}_{2}^{-}\right)$at near diffusion limited rates to yield peroxynitrite, a potent oxidising agent that may initiate lipid peroxidation in biological membranes, hydroxylation and nitration of aromatic amino acid residues, and sulfhydryl oxidation of proteins. ${ }^{9}{ }^{10}$ Furthermore, peroxynitrite may decompose to yield nitrogen dioxide and species with hydroxyl radical-like reactivity responsible for its toxicity. ${ }^{11}$ The stable oxidation end products of $\mathrm{NO}$ metabolism are nitrite $\left(\mathrm{NO}_{2}^{-}\right)$and nitrate $\left(\mathrm{NO}_{3}{ }^{-}\right) .{ }^{12}$ Peroxynitrite also reacts with tyrosine residues in protein to form stable 3-nitrotyrosine derivatives.

Cigarette smoking is associated with increased oxidative stress in the lung. ${ }^{13-18}$ The potent oxidant, superoxide, can be released from alveolar macrophages as well as polymorphonuclear leucocytes. ${ }^{16}{ }^{17}$ Cigarette smoke itself is also a rich source of oxidants ${ }^{19}$ and each puff of cigarette smoke contains approximately $10^{17}$ oxidant molecules. In habitual cigarette smokers exhaled NO levels are chronically decreased ${ }^{2021}$ possibly by downregulation of constitutive NOS (cNOS). ${ }^{21}$ It has recently been revealed that the reduction in exhaled NO levels in smokers is reversible and can increase following smoking cessation. ${ }^{22}$ It has been shown that acute exposure to cigarette smoke causes a reduction in exhaled NO levels 5 minutes after smoking which returns to baseline values within 15 minutes. ${ }^{21}$ In contrast, a consistent increase in the level of exhaled NO 1-10 minutes after smoking a cigarette has also been reported. ${ }^{23}$ These findings suggest that NO might be trapped at the epithelial surface of airways in the formation of bioequivalent oxides of nitrogen such as peroxynitrite and S-nitrosothiols. ${ }^{23}$

NO metabolites can be detected in the epithelial lining fluid of the human respiratory tract as well as in exhaled breath condensate. $^{2425}$
The aim of this study was to examine the short and long term effects of cigarette smoking by smokers on NO metabolism. The long term effect refers to differences between smokers and non-smokers, whereas the short term effect refers to changes in the NO metabolites in habitual smokers 30 and 90 
minutes after smoking exposure. We would therefore expect higher baseline levels of $\mathrm{NO}$ metabolites in smokers than in non-smokers because of the exogenous oxidative stress caused by cigarette smoke.

The reactive nitrogen metabolites such as $\mathrm{NO}_{2}^{-}, \mathrm{NO}_{2}^{-}+\mathrm{NO}_{3}^{-}$, S-nitrosothiols, and nitrotyrosine in exhaled breath condensate were measured, together with lung function and exhaled NO and carbon monoxide (CO) concentrations.

\section{Methods}

SUBJECTS

Twenty nine healthy volunteers (13 men) were allocated to two groups: non-smoking $(n=14$, mean (SD) age 34.8 (2.3) years) and smoking $(\mathrm{n}=15$, mean (SD) age 32.3 (2.4) years). The smokers had smoked a mean of 7.3 (2.0) pack years. Subjects with asthma, hypertension, or respiratory infection within the 2 weeks preceding the study were excluded. Measurement of exhaled $\mathrm{NO}$, exhaled $\mathrm{CO}$, lung function, and collection of exhaled breath condensate were performed. Spirometric tests showed that all subjects had a forced expiratory volume in one second $\left(\mathrm{FEV}_{1}\right)$ within the normal range. The clinical characteristics of the subjects are shown in table 1 .

Smokers were asked to refrain from smoking at least 4 hours before the baseline measurements. After assessing the baseline measurements, smokers were asked to smoke two cigarettes and the measurements were then repeated 30 and 90 minutes later. Each individual smoked cigarettes from the same brand during the study (Marlboro filter cigarettes, Philip Morris, Richmond, USA).

The study protocol was approved by the ethics committee of the Royal Brompton Hospital and informed consent was obtained from each subject.

\section{PULMONARY FUNCTION}

Forced vital capacity (FVC) \% predicted and $\mathrm{FEV}_{1} \%$ predicted were measured using a dry spirometer (Vitalograph Ltd, Buckingham, UK) and the best value of three manoeuvres was expressed as a percentage of the predicted value.

\section{EXHALED NO MEASUREMENT}

Exhaled NO was measured by chemiluminescence analyser (Model LR2000, Logan Research Ltd, Rochester, UK) with a sensitivity to $\mathrm{NO}$ of $1-500 \mathrm{ppb}$ by volume and a resolution of $0.3 \mathrm{ppb}$. The analyser was designed for online recording of exhaled NO concentrations. It was

Table 1 Subject characteristics

\begin{tabular}{lll}
\hline & Healthy smokers $(n=15)$ & Healthy non-smokers $(n=14)$ \\
\hline Age (years) & $32(2)$ & $35(2)$ \\
Sex $(M / F)$ & $7 / 8$ & $6 / 8$ \\
FVC $(\%$ predicted) & $97.1(3.1)$ & $100.5(3.1)$ \\
FEV $1 \%$ predicted $)$ & $90.1(1.4)[87.07$ to 93.11$]$ & $101.1(2.6)[95.45$ to 106.76$]$ \\
Exhaled NO $(\mathrm{ppb})$ & $4.3(0.3)^{\star}[3.59$ to 4.93$]$ & $5.5(0.5)[4.46$ to 6.48$]$ \\
Exhaled CO $(\mathrm{ppm})$ & $12.5(2.2)^{\star \star}[7.85$ to 17.20$]$ & $3.5(0.3)[2.83$ to 4.13$]$ \\
\hline
\end{tabular}

$\mathrm{FEV}_{1}=$ forced expiratory volume in one second $\mathrm{FVC}=$ forced vital capacity; $\mathrm{NO}=$ nitric oxide $\mathrm{CO}=$ carbon monoxide

monoxide. Values are means (SE) [95\% confidence intervals].

${ }^{\star} \mathrm{p}<0.05 ;{ }^{\star \star} \mathrm{p}<0.001$ calibrated with certified NO mixtures ( $55 \mathrm{ppb}$ ) in nitrogen (BOC Special Gases, Guildford, $\mathrm{UK})$. Measurement of exhaled NO was made by slow exhalation (5-6 1/min) from total lung capacity (TLC) for $20-25$ seconds against a resistance (3 (0.4) $\mathrm{mm} \mathrm{Hg}$ ) to prevent nasal contamination. The mean values were taken from the point corresponding to the plateau of the end exhaled $\mathrm{CO}_{2}$ reading, representing the lower respiratory tract sample.

EXHALED CO MEASUREMENT

Exhaled $\mathrm{CO}$ was measured using a modified electrochemical sensor with a sensitivity of 1-500 ppm CO simultaneously with NO measurement by LR2000 chemiluminescence analyser (Logan Research Ltd) to control exhalation parameters (resistance $3(0.4) \mathrm{mm} \mathrm{Hg}$; exhalation flow $5-61 / \mathrm{min})$. The mean value of two measurements was recorded. Ambient CO was recorded before each measurement and subtracted from the mean value obtained during the manoeuvres.

\section{EXHALED BREATH CONDENSATE}

Exhaled breath condensate was collected using a condenser which allowed the non-invasive collection of non-gaseous components of the expiratory air (EcoScreen, Jaeger, Würzburg, Germany). Subjects breathed through a mouthpiece and a two way non-rebreathing valve which also served as a saliva trap. They were asked to breathe at a normal frequency and tidal volume, wearing a noseclip, for a period of 10 minutes. The condensate (at least $1 \mathrm{ml}$ ) was collected as ice at $-20^{\circ} \mathrm{C}$ and immediately stored at $-70^{\circ} \mathrm{C}$.

\section{NITRITE, NITRITE + NITRATE, AND}

S-NITROSOTHIOL MEASUREMENT

Quantification of $\mathrm{NO}_{2}^{-}$was assessed by a fluorometric assay based on the reaction of nitrite with 2,3-diaminonaphthalene (DAN) to form the fluorescent product 1-(H)-naphthotriazole. ${ }^{26}$ Briefly, a $100 \mu \mathrm{l}$ sample of exhaled breath condensate was mixed with $10 \mu \mathrm{l}$ of $0.05 \mathrm{mg} / \mathrm{ml}$ DAN reagent in $0.625 \mathrm{M} \mathrm{HCl}$. The reaction was allowed to proceed at room temperature in the dark and was terminated with $10 \mu \mathrm{l}$ of $1.4 \mathrm{M}$ $\mathrm{NaOH}$. The intensity of the fluorescent signal produced by the product was immediately measured by a fluorometer (Ex: $360 \mathrm{~nm}, \mathrm{Em}$ : 460 nm; Biolite F1, Labtech International Ltd, Uckfield, UK). Incubation of samples with nitrate reductase allowed the nitrate present in the sample to be measured by this assay after being converted to nitrite.

S-nitrosothiols were measured following release of nitrite from nitrosothiols by $2 \mathrm{mM}$ mercuric chloride $\left(\mathrm{HgCl}_{2}\right)$ using the above mentioned procedure. To calculate S-nitrosothiols, nitrite levels were subtracted.

NITROTYROSINE ASSAY

Nitrotyrosine was measured using a specific enzyme immunoassay (EIA) (Cayman Chemical, Ann Arbor, MI, USA). Assays were initially performed on unconcentrated condensate 
samples. The lower limit of detection for this assay was $3.9 \mathrm{ng} / \mathrm{ml}$. If nitrotyrosine was not detected in unconcentrated condensate samples, the breath condensates were concentrated threefold using a freeze dryer (Modulyo, Edwards, Crawley, UK) and reanalysed.

STATISTICAL ANALYSIS

Data are reported as mean (SE) and confidence intervals. The study population had a normal distribution so the comparisons between smoker and non-smoker groups were performed using Student's $t$ tests. The time course of the effect of cigarette smoking was investigated by repeated measures ANOVA. The significance level was defined as $\mathrm{p}<0.05$.

Statistical calculations were carried out using the Statistica 5.1 statistical program package (StatSoft Inc, Tulsa, Oklahoma, USA).

\section{Results}

BASELINE LEVELS OF EXHALED NO, CO, AND

NITRIC OXIDE METABOLITES

Concentrations of $\mathrm{NO}$ in the exhaled air were significantly decreased in cigarette smokers compared with normal non-smokers (4.3 (0.3), $95 \%$ CI 3.59 to 4.93 ppb v 5.5 (0.5), $95 \%$ CI 4.46 to $6.48 \mathrm{ppb}$; $<<0.05)$. The difference in exhaled NO was -1.21 with a lower $95 \%$ confidence limit of -2.35 and an upper confidence limit of -7.41 .
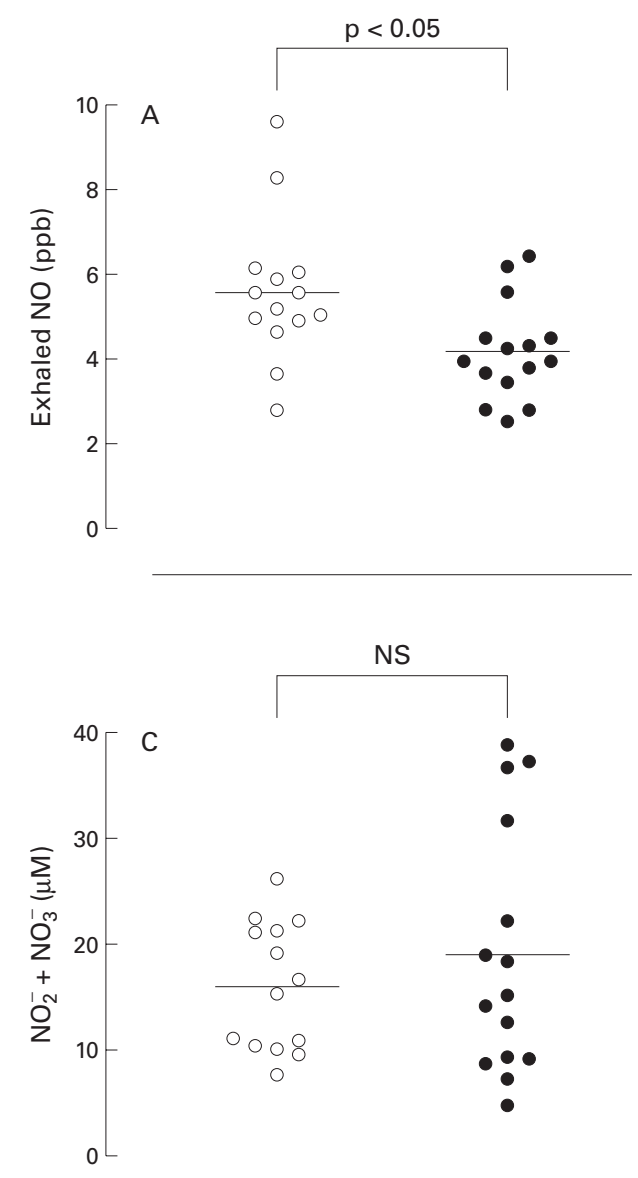

Non-smokers

Smokers

Exhaled CO concentrations were significantly higher in smokers than in non-smokers (12.5 (2.2), 95\% CI 7.85 to 17.20 ppm $v 3.4$ (0.3), 95\% CI 2.83 to $4.13 \mathrm{ppm}$; p<0.001). The difference in exhaled CO was 9.04 with a $95 \%$ lower confidence limit of 4.37 and an upper confidence limit of 13.72. There was no significant difference between smokers and non-smokers in the levels of $\mathrm{NO}_{2}^{-}$(2.4 (0.3), $95 \%$ CI 1.63 to $30.8 \mu \mathrm{M} v 3.2(0.5), 95 \% \mathrm{CI}$ 2.25 to $4.4 \mu \mathrm{M}), \mathrm{NO}_{2}^{-}+\mathrm{NO}_{3}^{-}(20.2(2.8), 95 \%$ CI 14.30 to $26.19 \mu \mathrm{M} v 16.0(1.6), 95 \% \mathrm{CI}$ 12.56 to $19.50 \mu \mathrm{M})$, S-nitrosothiols $(0.1(0.1)$, $95 \% \mathrm{CI}-0.03$ to $0.33 \mu \mathrm{M} v 0.5(0.2), 95 \% \mathrm{CI}$ 0.02 to $0.94 \mu \mathrm{M})$, or nitrotyrosine $(7.2$ (1.3) $\mathrm{ng} / \mathrm{ml} v 6.3(0.8) \mathrm{ng} / \mathrm{ml}$; fig 1 .

LEVELS OF EXHALED NO, CO, AND NO METABOLITES AFTER EXPOSURE TO TOBACCO SMOKE

To determine the effects of cigarette smoke on exhaled $\mathrm{NO}, \mathrm{CO}$ and $\mathrm{NO}$ metabolites $\mathrm{NO}_{2}^{-}$, $\mathrm{NO}_{2}{ }^{-}+\mathrm{NO}_{3}{ }^{-}, \mathrm{S}$-nitrosothiols, and nitrotyrosine were measured in exhaled breath condensate of habitual smokers 30 and 90 minutes after smoking two cigarettes. The effect on $\mathrm{NO}_{2}^{-}+$ $\mathrm{NO}_{3}{ }^{-}$was investigated by repeated measures ANOVA and a significant main effect was found $(\mathrm{F}(2,28)=3.89, \mathrm{p}<0.03)$. Mauchley's test proved that $\mathrm{NO}_{2}^{-}+\mathrm{NO}_{3}^{-}$did not violate
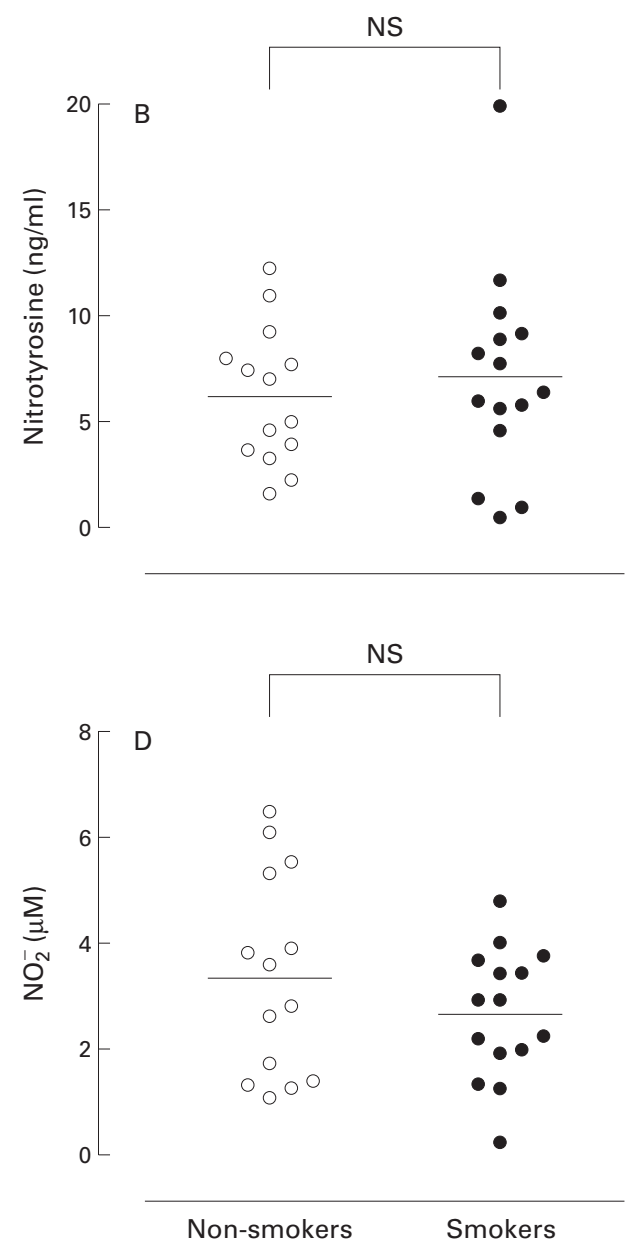

Figure 1 Concentrations of $(A)$ exhaled nitric oxide (NO), (B) nitrotyrosine, $(C)$ nitrite + nitrate $\left(\mathrm{NO}_{2}^{-}+\mathrm{NO}_{3}^{-}\right)$, and (D) nitrite $\left(\mathrm{NO}_{2}^{-}\right)$in breath condensate in healthy non-smokers and smokers. Exhaled $\mathrm{NO}$ was significantly decreased in smokers $(p<0.05)$ but there was no significant difference in the levels of NO metabolites in exhaled breath condensate. 
the sphericity assumption. Planned comparisons were performed to compare the levels of $\mathrm{NO}_{2}^{-}+\mathrm{NO}_{3}^{-}$before and after smoking (30 and 90 minutes, respectively). The change in $\mathrm{NO}_{2}^{-}$ $+\mathrm{NO}_{3}^{-}$levels at baseline compared with 30 minutes after smoking $(20.2(2.8) \mu \mathrm{M} v 29.8$ (3.4) $\mu \mathrm{M})$ was significant $(\mathrm{F}(1,14)=7.32$, $\mathrm{p}<0.017)$ and returned to the baseline level within 90 minutes (21.8 (3.6) $\mu \mathrm{M}, \mathrm{p}<0.05)$; the difference between the levels measured at 30 and 90 minutes was also significant $(\mathrm{F}(1,14)=6.97, \mathrm{p}<0.019)$; fig 2$)$. There was no change in exhaled NO concentration (4.3 (0.3) ppb $v 4.2(0.4) \mathrm{ppb})$ or in the concentrations of $\mathrm{NO}_{2}^{-}$, S-nitrosothiols, or nitrotyrosine at 30 or 90 minutes after smoking exposure. The main effect of the repeated measures ANOVA calculated on exhaled CO was significant $(\mathrm{F}(2,28)=13.28, \mathrm{p}<0.003)$. The F-test
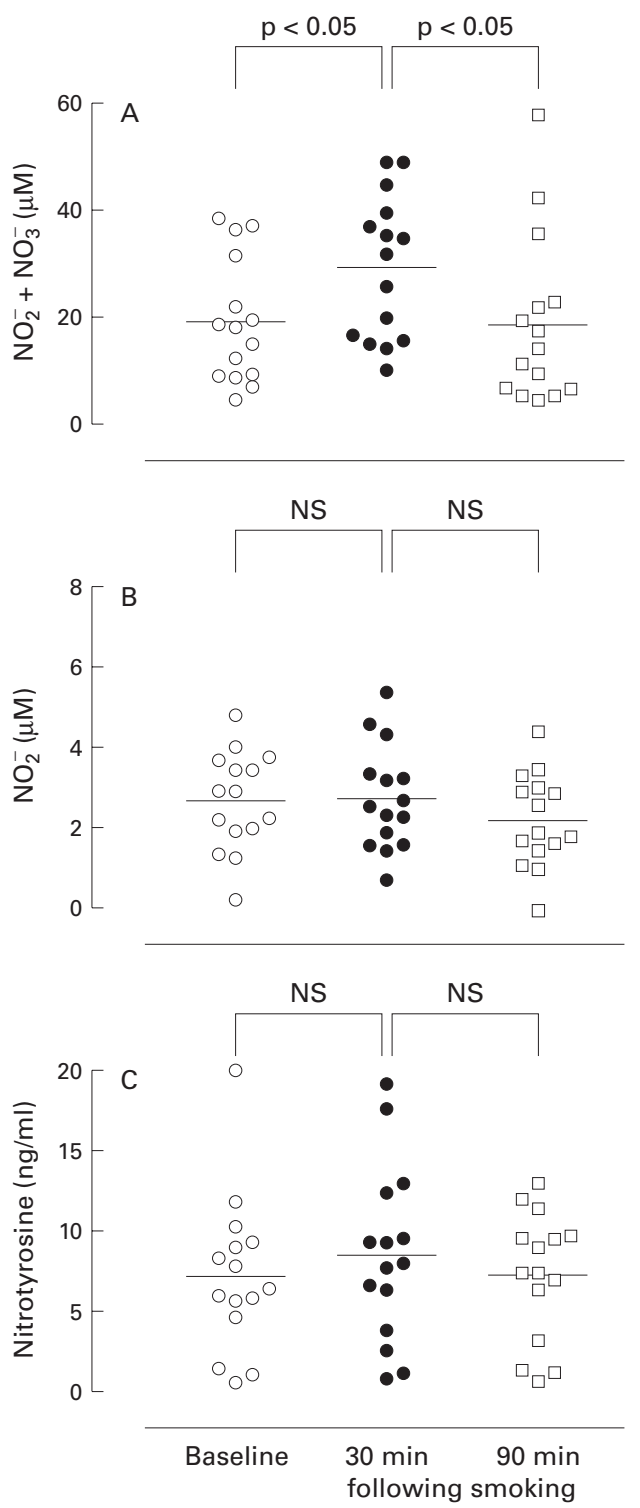

Figure 2 Concentrations of $(A)$ nitrite + nitrate $\mathrm{NO}_{2}^{-}+$ $\left.\mathrm{NO}_{3}^{-}\right),(\mathrm{B})$ nitrite $\left(\mathrm{NO}_{2}^{-}\right)$, and $(\mathrm{C})$ nitrotyrosine in exhaled breath condensate after smoking challenge. $\mathrm{NO}_{2}^{-}+$ $\mathrm{NO}_{3}^{-}$concentrations were significantly increased 30 minutes after smoking $(p<0.05)$ and returned to the baseline level within 90 minutes $(p<0.05)$. There were no significant changes in the concentrations of $\mathrm{NO}_{2}^{-}$and nitrotyrosine after exposure to tobacco smoke. was adjusted by the Greenhouse-Geisser correction as the Mauchley sphericity test was significant. Concentrations of exhaled $\mathrm{CO}$ increased significantly from the baseline levels to the levels measured at 30 minutes after smoking (12.5 (2.2) ppm v 19.6 (3.0) ppm; $\mathrm{F}(1,14)=35.76, \mathrm{p}<0.0003)$, and there was also a significant difference between the levels at 30 and 90 minutes (19.6 (3.0) ppm $v 14.1$ (2.5) ppm; $\mathrm{F}(1,14)=14.88, \mathrm{p}<0.0017)$.

There was no correlation between levels of exhaled NO and NO metabolites in breath condensate before and after exposure to tobacco smoke.

\section{Discussion}

In this study the acute and long term effects of smoking exposure on NO metabolites in exhaled breath condensate in healthy smokers were examined and compared with values in normal subjects.

The concentration of exhaled NO was reduced significantly in current smokers compared with normal non-smoking subjects, in agreement with other studies. ${ }^{20-23}$ There was no significant difference in the levels of $\mathrm{NO}_{2}^{-}$, $\mathrm{NO}_{2}^{-}+\mathrm{NO}_{3}^{-}$, S-nitrosothiols, or nitrotyrosine between habitual smokers at baseline and nonsmokers. Thirty minutes after smoking two cigarettes there was no significant change in the concentration of exhaled NO but the concentrations of $\mathrm{NO}$ metabolites $\left(\mathrm{NO}_{2}^{-}+\mathrm{NO}_{3}{ }^{-}\right)$were significantly increased. This increase was transient and returned to the baseline value by 90 minutes.

Many investigators have reported reduced production of $\mathrm{NO}$ in the lower respiratory tract of habitual smokers between cigarette ${ }^{20-23}$ and exhaled NO concentrations return to normal on cessation of smoking. ${ }^{22}$ Cigarette smoke itself contains high concentrations of $\mathrm{NO}$ and $\mathrm{CO}$ which may directly inhibit NO production by inhibition of NOS. ${ }^{27}{ }^{28}$ However, other constituents of cigarette smoke may play a role in the reduction of exhaled NO. ${ }^{20} \mathrm{NO}$ itself is a highly reactive molecule which can be rapidly oxidised and react with other biomolecules such as superoxide. ${ }^{3-8}$ Cigarette smoke not only contains oxidants, but also generates an increased release of oxidants from neutrophils and macrophages. ${ }^{16}{ }^{17} \mathrm{NO}$ and superoxide anion can react to form peroxynitrite by a rapid near diffusion limited reaction ${ }^{29}{ }^{30}$ which can nitrate tyrosine residues in proteins yielding nitrotyrosine derivatives. ${ }^{30}$ Since the level of exhaled NO is lower and superoxide release is increased in habitual smokers, it is possible that there is increased oxidative metabolism of $\mathrm{NO}$ in cigarette smokers. $\mathrm{NO}_{2}^{-}$and $\mathrm{NO}_{3}^{-}$, the $\mathrm{NO}$ oxidation products, can be detected in the sputum and epithelial lining fluid of the normal human respiratory tract, as well as in exhaled breath condensate. ${ }^{242531}$ Although lower levels of exhaled NO were observed in smokers at baseline in our study, there was no difference in NO oxidative metabolites in exhaled breath condensate between healthy smokers and nonsmokers. Taken together, these data suggest that the exogenous oxidative stress induced by cigarette smoking may not exert a long term 
effect on NO oxidation in vivo, and the lower levels of exhaled NO in smokers may be the result of decreased production from NOS rather than from increased metabolism.

Data regarding the acute effects of smoking exposure remain controversial. Kharitonov et al observed a significant decrease in the concentration of exhaled NO 5 minutes after smoking, suggesting cNOS downregulation by cigarette smoke. ${ }^{21}$ In contrast, Chambers et al reported a small but highly consistent increase in the concentration of exhaled NO following smoking, which suggests that $\mathrm{NO}$ is trapped at the epithelial surface of the normal human lower respiratory tract in formation of bioequivalent oxides of nitrogen and that this trapping mechanism is redox sensitive. ${ }^{23}$ Our study partly supports this hypothesis because we found a significant increase in $\mathrm{NO}_{2}^{-}+\mathrm{NO}_{3}^{-}$as the acute effect of smoking. However, there was no change in the levels of $\mathrm{NO}_{2}^{-}, \mathrm{S}$-nitrosothiols, or nitrotyrosine in exhaled breath condensate following smoking exposure. It is unclear why $\mathrm{NO}_{3}^{-}$was high compared with $\mathrm{NO}_{2}^{-}$, $\mathrm{S}$-nitrosothiols, and nitrotyrosine. It has been shown that superoxide released from activated polymorphonuclear neutrophils can decrease NO by conversion to nitrate, suggesting a potential mechanism for modulation of NO levels in vivo. ${ }^{32}$ It is possible to convert from nitrite to nitrate under acidic conditions, which might be found in the setting of cell death and lysis. ${ }^{32}$ It suggests that smoking can modulate NO biochemistry, causing a transiently higher concentration of reactive nitrogen species.

There was no significant difference in the levels of nitrotyrosine in breath condensate between smokers and non-smokers, and there was no change following smoking exposure. One possible reason for the lack of change may be that cigarette smoke itself may either decrease nitrotyrosine formation or increase its breakdown.

Our data suggest that the acute oxidative stress presented to the lung by cigarette smoke leads to locally transiently increased oxidation in the lower airways, facilitating oxidation of $\mathrm{NO}$ and resulting in an increase in NO oxidative end products. After oxidant challenge NO metabolites are likely to be removed from the airways via the bloodstream and the antioxidative system of the lung. NO metabolites then return to baseline levels. This recovery might be more difficult in diseased lung such as in chronic obstructive pulmonary disease (COPD) or asthma.

Although the small sample size limited the study, all the differences proved to be significant. The time course of the effect of cigarette smoking on NO metabolites also revealed a discernible pattern. Presumably, serial measurement between baseline and 90 minutes after smoking might reveal a more detailed analysis of the change in NO metabolites.

In summary, we conclude that cigarette smoke can modulate NO metabolism by facilitating the oxidation of $\mathrm{NO}$ to increase transiently oxidative products, which may contribute to the detrimental effect of cigarette smoke on the airways. However, the lack of a long term effect of exogenous oxidative stress induced by cigarette smoking on NO metabolites suggests that other pathways may play a greater role in its damaging effect. Further studies are needed to investigate the complex chemistry of other highly harmful oxidative products such as peroxynitrite in the airways after exposure to tobacco smoke.

This study was supported by the British Lung Foundation (NHLI, UK), the Hungarian Respiratory Society, and Foundation for Patients with Lung \& Heart Diseases (Hungary).

1 Barnes PJ, Belsivi MG. Nitric oxide and lung disease. Thorax 1993;48:1034-43.

2 Moncada S, Palmer RMJ, Higgs EA. Nitric oxide: physiology, pathology and pharmacology. Pharmacol Rev 1991;43:109-41.

3 Van der Vliet A, Eiserich JP, Shigenaga MK, et al. Reactive nitrogen species and tyrosine nitration in the respiratory tract. Am $\mathcal{F}$ Respir Crit Care Med 1999;160:1-9.

4 Kroncke K, Fehsel DK, Kolb-Bachofen V. Nitric oxide: cytotoxicity versus cytoprotection-how, why, when and where? Nitric Oxide: Biol Chem 1997;1:107-20.

5 Beckman JS, Koppenol WH. Nitric oxide, superoxide, and peroxynitrite: the good, the bad, and the ugly. Am $\mathcal{F}$ Physiol 1996;271 (Cell Physiol 40):C1424-37.

6 Palmer RMJ, Ferrige AG, Moncada S. Nitric oxide release accounts for the biological activity of endothelium-derived relaxing factor. Nature 1987;327:524-6.

7 Parks NJ, Krohn KA, Mathis CA, et al. Nitrogen-13-labelled nitrite and nitrate: distribution and metabolism after intratracheal administration. Science 1981;212:58-61.

8 Gaston B, Drazen JM, Loscalzo J, et al. The biology of nitrogen oxides in the airways. Am f Respir Crit Care Med 4;149:538-51.

9 Radi RJ, Beckman JS, Bush KM, et al. Peroxynitrite oxidation of sulfhydryls. 7 Biol Chem 1991;266:4244-50.

10 Radi RJ, Beckman JS, Bush KM, et al. Peroxynitrite-induced membrane lipid peroxydation: the cytotoxic potential of superoxide and nitric oxide. Arch Biochem Biophys 1991; 288:484-7.

11 Beckman JS, Beckman TW, Chen J, et al. Apparent hydroxyl radical production by peroxynitrite: implications for endothelial injury from nitric oxide and superoxide. Proc Natl Acad Sci USA 1990;87:1620-4

12 Dweik RA, Laskowski D, Abu-Soud HM, et al. Nitric oxide synthesis in the lung. Regulation by oxygen through a kinetic mechanism. F Clin Invest 1998;101:660-6.

13 Rahman I, Morrison D, Donalson K, et al. Systemic oxidative stress in asthma, COPD, and smokers. Am F Respir Crit Care Med 1996;154:1055-60.

14 Morrison D, Lannan S, Langride A, et al. Effect of cigarette smoking on epithelial permeability, inflammation and oxidant status in airspaces of chronic smokers. Thorax 1994;49:1077.

15 Hoidal JR, Fox RB, LeMarbe PA, et al. Altered oxidative metabolic responses in vitro of alveolar macrophages from asymptomatic cigarette smokers. Am Rev Respir Dis 1981;123:85-9

16 Ludwig PW, Hoidal JR. Alterations in leukocyte oxidative metabolism in cigarette smokers. Am Rev Respir Dis 1982; 126:977-80

17 Hubbard RC, Ogushi F, Fels GA, et al. Oxidants spontaneously released by alveolar macrophages of cigarette mokers can inactivate the active site of $\alpha_{1}$-antitrypsin, rendering it ineffective as an inhibitor of neutrophil elastase. $\mathcal{F}$ Clin Invest 1987;80:1289-95.

18 Repine JE, Bast A, Lankhorst I, et al. Oxidative stress in chronic obstructive pulmonary disease. Am F Respir Crit Care Med 1997;156:341-57.

19 Pryor WA, Stone K. Oxidants in cigarette smoke: radicals, hydrogen peroxide, peroxynitrate, and peroxynitrite. Ann NY Acad Sci 1993;686:12-28.

20 Schilling J, Holzer P, Guggenbach $M$, et al. Reduced endogenous nitric oxide in the exhaled air of smokers and hyperenous nitric oxide in the exhaled air of

21 Kharitonov SA, Robbins RA, Yates D, et al. Acute and Kharitonov SA, Robbins RA, Yates $\mathrm{D}$, et al. Acute and
chronic effects of cigarette smoking on exhaled nitric oxide. Am 7 Respir Crit Care Med 1995;152:609-12.

22 Robbins RA, Millatmal T, Lassi K, et al. Smoking cessation is associated with an increase in exhaled nitric oxide. Chest 1971;12:313-8.

23 Chambers DC, Tunnicliffe WS, Ayres JG. Acute inhalation of cigarette smoke increases lower respiratory tract nitric oxide concentrations. Thorax 1998;53:677-9.

24 Gaston B, Reilly J, Drazen JM, et al. Endogenous nitrogen oxides and bronchodilator S-nitrosothiols in human airways. Proc Natl Acad Sci USA 1993;90:10957-61.

25 Ho LP, Innes JA, Greening AP. Nitrite levels in breath condensate of patients with cystic fibrosis is elevated in contrast to exhaled nitric oxide. Thorax 1998;53: in contra-4.

26 Misko TP, Schilling RJ. Salvemini D, et al. A fluorometric assay for the measurement of nitrite in biological samples. Anal Biochem 1993;214:11-16. 
27 Assreuy J, Cunha FQ, Liew FY, et al. Feedback inhibition of nitric oxide synthase by nitric oxide. $\mathrm{Br} f$ Pharmacol 1993;108:833-7.

28 White KA, Marletta MA. Nitric oxide synthase is a cytochrome P-450 type hemoprotein. Biochemistry 1992; 31:6627-31.

29 Miles A, Bohle DS, Glassbrenner PA, et al. Modulation of superoxide-dependent oxidation and hydroxylation reactions by nitric oxide. $\mathcal{F}$ Biol Chem 1996;271:40-7.
30 Beckman JS. Oxidative damage and tyrosine nitration from peroxynitrite. Chem Res Toxicol 1996;9:836-44.

31 Rutgers SR, van der Mark ThW, Coers W, et al. Markers of nitric oxide metabolism in sputum and exhaled air are not increased in chronic obstructive pulmonary disease. Thorax 1999;54:576-80.

32 Jones KL, Bryan TYW, Jinkins PA, et al. Superoxide released from neutrophils causes a reduction in nitric oxide gas. Am f Physiol 1998;275(Lung Cell Mol Physiol 19): L1120-6.

\section{1st Asia Pacific Forum on Quality Improvement in Health Care}

\section{Three day conference}

\section{Wednesday 19 to Friday 21 September 2001 Sydney, Australia}

We are delighted to announce this forthcoming conference in Sydney. Authors are invited to submit papers (call for papers closes on Friday 6 April), and delegate enquiries are welcome. The themes of the Forum are:

- Improving patient safety

- Leadership for improvement

- Consumers driving change

- Building capacity for change: measurement, education and human resources

- The context: incentives and barriers for change

- Improving health systems

- The evidence and scientific basis for quality improvement.

Presented to you by the BMJ Publishing Group (London, UK) and Institute for Healthcare Improvement (Boston, USA), with the support of the the Commonwealth Department of Health and Aged Care (Australia), Safety and Quality Council (Australia), NSW Health (Australia), and Ministry of Health (New Zealand).

For more information contact: quality@bma.org.uk or fax +44(0)20 73836869 